\title{
An Analysis on the Factors Influencing College Students' Intention to Post-graduate Study in Guangdong
}

\author{
Li Peiliang ${ }^{1}$ \\ Guangdong University of Finance \& Economics, \\ Guangdong Province, Guangzhou City, Haizhuqu District Road No. 21 Luntou,510320.
}

Key words: postgraduate entrance exam, influencing factors, logistic model

\begin{abstract}
After analyzing previous literature views on factors affecting college students' intention to postgraduate study and interviewing college staff and students, this study designed a questionnaire to further study those factors. By interviewing students from five universities and using statistical methods, the author build a mathematical model, which not only can explain those various factors but also can identify the degree of students' intentions to post-graduate study. Finally, this paper puts forward five suggestions of the actual value of the model.
\end{abstract}

\section{Background}

Since China reopened College Entrance Examination and Graduate enrollment in 1978, particularly after "People's Republic of China 's Degree Ordinance" was promulgated in 1981, graduate education reform and development has been conducted for more than thirty years. Graduate education in our country has been rapidly developing. The number of postgraduate students increases rapidly, from $10708^{1}$ in 1978 to 574300 in $2015^{2}$. The average rate of increasing enrollment number is $11.37 \%$. Because of the China popularization of higher education, the employment pressure on college graduates has increased year by year. In 2002-the year right before College enrollment expansion in China, only 1.45 million Chinese college students were hired. In 2015, the number of employed people graduating from universities has reached 7,490,000 ${ }^{3}$. The number of employed people graduating from universities increased 5.2 times during the 13 years.

Comparing the two sets of figures above, we can roughly explain the reason why post-graduate education candidates keep increasing. But by further analyzing the relation curve of the number of graduate applicants of the last 15 years, the author of this paper finds that the number doesn't present a tendency of straight climb, especially during 2008 to 2009 and 2014 to 2015, the number of candidates has dropped, which indicates an issue that needs to be studied--What factors affect the intention of graduates for further study. These factors need to use empirical methods to study and conclude the regular pattern, forming a mathematical model which can test and operate the number. These factors, data and models not only will help college admissions departments adjust their future enrollment plan, but also will help university students affairs departments and secondary college departments' executives adjust the cultivation directions of different majors, and thus help college students make better career plan.

\section{Literature Review}

Most related previous literature research analyzes this issue from perspectives such as the national policy, the student enrollment plan, cost comparison for further study and psychology of

1Li Peiliang; Male;1981.1;Place of origin: Kaifeng, He Nan; Nation:Han; Company:Guangdong University of Finance \& Economics, School of Mathematics and Statistics;Title: Lecturer, Master. Research area: Higher Education, University student behavior; Address: Guangdong Province, Guangzhou City, Haizhuqu District Road No. 21 Luntou,510320. 
employment. There are some other researches analyzing the influencing factors from angles of social science and economics. Here is a list of several main viewpoints. Chen Zhifeng (1997) believes that reasons why the number of students who apply for postgraduate degree changes are: the national graduate enrollment policy, social and political situation, graduate enrollment plan and Graduate Enrollment professional structure adjustment ${ }^{4}$; Xiao Zhanfeng (2008) believes that the employment situation and their GPA will affect whether students want to be postgraduate students ${ }^{5}$; Zheng Jun, Yang Guang think that the interaction of survival pressure (or 'job stress') and students' rational choice leads to students' intention for further study; students' motivation for postgraduate degree arose from survival needs, but with more and more people join this group and the tendency for further study form gradually, the social motivation and economy motivation become more important ${ }^{6}$; Shangguan Jian (2007) analyzes this issue from a sociological perspective and he believes there are 3 reasons: Getting a postgraduate degree enables students to have more opportunities to become a upper class from lower class; the change of postgraduate students' employment environment and the comparison of the inputs and outputs of education; the overall disorder of postgraduate students education revolution or the decrease of education quality ${ }^{7}$; After investigation ,Lu Jie (2007) found that the motivation for further study is various and complicated, those factors including: academic study, employment and obsession for prestigious university, expectations from parents, registered permanent residence, the group effect ${ }^{8}$; Zhou ye (2011) uses factor analysis method to analyze this issue and he believes that postgraduate motivation factor intensity orders are working needs, self realization, ambition to get promotion, social environment ${ }^{9}$.Through investigation, Liu Tianjun (2013) thinks that the group effect and the reality of dissatisfaction for majors are the other two factors ${ }^{10}$. Most current literature researches get conclusion on the basis of theories induce, a few scholars use the analysis of survey to summarize the reasons, but they lack mathematical model for operation and forecasting. In view of this, based on the empirical investigation, this paper uses statistical software to build data model, and put forward some suggestions based on the model.

\section{Survey Methodology and Model}

Build preliminary questionnaire and test reliability and validity

According to the previous point of view, the author of the paper interviewed some college students, college students work-related experts and professional counselors' interview, and summed up the impact of the factors. Design preliminary questionnaire to investigate 180 college students, test the the significant correlation coefficient test matrix obtained by SPSS17.0 software, the result is that the significant correlation coefficients test $p$ value is smaller than 0.05 , indicating that there is a strong correlation between the original variables, and thus it is necessary to carry on the factor analysis.

From KMO and Bartlett spherical test (as shown in Table 1), the KMO statistic is 0.734578 , the Bartlett value of $\mathrm{P}$ is $2.3 \mathrm{E}-100<0.05$, which shows that the data is suitable for factor analysis.

Table 1 KMO and Bartlett's Test

\begin{tabular}{|c|c|l|}
\hline \multicolumn{2}{|c|}{$\begin{array}{c}\text { Kaiser-Meyer-Olkin Measure of Sampling } \\
\text { Adequacy. }\end{array}$} & 0.734578 \\
\hline \multirow{3}{*}{ Bartlett's Test of Sphericity } & Approx. Chi-Square & 1066.888 \\
\cline { 2 - 3 } & & \\
\cline { 2 - 3 } & df & 253 \\
\hline
\end{tabular}

The Alpha coefficient of Cronbach was used to analyze the reliability of the initial test questionnaire. The Alpha coefficient of each factor is between $0.794 \sim 0.915$, and the internal consistency coefficient of the questionnaire was 0.825 . The characteristic values of the 9 public factors are above 0.921 , which accounts for $69.62 \%$ of the variance. This shows that the 9 factors in 
the structure reflect the impact of college students in the composition of the entrance exam. Statistical analysis shows that correlation coefficient of the nine public factor score and total score is between the 0.283 0.586, which means positive correlation statistical significance $(\mathrm{P}<0.01)$. It indicates that the content of that each factor test matches the content of the overall questionnaire, which means the initial test of content validity of the questionnaire is high.

Formal investigation and establishment of model

This paper investigates five universities of Guangdong Province: a comprehensive national prestigious university: Sun Yat sen University; a science and Engineering National prestigious University: South China University of Technology; famous overseas Chinese universities: Jinan University; a Medical University, Guangdong University of traditional Chinese medicine; a financial type university: Guangdong University of Finance and economics. The investigation lays emphasis on the control of the implementation of the environment to ensure the reliability of the survey standards. 1352 questionnaires were sent and a total of 1322 questionnaires were recovered, and the recovery rate was $97.93 \%$.

This paper uses SAS to process all the data obtained, according to the software operation, the following results are obtained:

Table 2 Maximum likelihood estimation of Logistc program analysis table

\begin{tabular}{cccccc}
\multicolumn{5}{c}{ Standard } & \multicolumn{3}{c}{ Wald } \\
Parameter & DF & Estimate & Error & Chi-Square & Pr $>$ ChiSq \\
Intercept & 1 & -2.3554 & 0.6338 & 13.8111 & $0.0002^{*}$ \\
q1 & 1 & -0.2320 & 0.1352 & 2.9453 & $0.0861^{*}$ \\
q2 & 1 & 0.2879 & 0.1889 & 2.3215 & $0.1276^{*}$ \\
q8father & 1 & 0.4409 & 0.3173 & 1.9309 & $0.1647^{*}$ \\
q10 & 1 & 0.4169 & 0.4648 & 0.8046 & 0.3697 \\
q11 & 1 & 0.2473 & 0.2611 & 0.8977 & 0.3434 \\
q12 & 1 & 0.3544 & 0.2842 & 1.5549 & 0.2124 \\
q13 & 1 & 0.5211 & 0.2902 & 3.2241 & $0.0726^{*}$ \\
q14 & 1 & 0.6011 & 0.2913 & 4.2595 & $0.0390^{*}$ \\
q15 & 1 & -0.0282 & 0.3110 & 0.0082 & 0.9277 \\
q16 & 1 & -0.5849 & 0.3358 & 3.0345 & $0.0815^{*}$ \\
q17 & 1 & 0.0137 & 0.3691 & 0.0014 & 0.9704 \\
q18 & 1 & 0.1258 & 0.3541 & 0.1262 & 0.7224 \\
q19 & 1 & 0.5828 & 0.2808 & 4.3074 & $0.0379^{*}$ \\
q23 & 1 & -0.4534 & 0.2683 & 2.8549 & $0.0911^{*}$
\end{tabular}

$* \operatorname{Pr}<0.15, * * \operatorname{Pr} \approx 0.15$

From table 2, we can see that in * $\operatorname{Pr}<0.15$ for standard, Q1, Q2, q8father, q13, 13q14, Q16, Q19, q23, main effect of the eight factors is very significant, each of the factors represents: grade, gender, father's culture level, how much pocket money a month, part-time job capacity, academic level of last year, interpersonal relationship pressure.

According to the coefficients of each significant factor in Table 2, the Logistc model is obtained as follows:

$$
\begin{aligned}
& \mathrm{F}(\mathrm{x})=\log i t p=\ln \frac{p}{1-p}=-2.3554-0.232 \mathrm{x}_{1}+0.2879 \mathrm{x}_{2}++0.4409 \mathrm{x}_{3}+0.5211 \mathrm{x}_{4}+0.6011 \mathrm{x}_{5}-0.5849 \\
& \mathrm{x}_{6}+0.5828 \mathrm{x}_{7}-0.4534 \mathrm{x}_{8}
\end{aligned}
$$

\section{Model and Result Overview}

Explanation of the model

According to the Logistc model above, $z=a+b x_{1}+c x_{2}+\Lambda+z x_{k}$, put the $\mathrm{Z}$ into the model, 
$\mathrm{Z}$ and $\mathrm{P}$ is a monotone increasing function. This shows that the tendency of college students choosing to get postgraduate degree is determined by $\mathrm{z}$, which means that the tendency is influenced by the 8 factors. When all the $\mathrm{x}_{\mathrm{k}}$ whose coefficient is negative is all 0 , and all the $\mathrm{x}_{\mathrm{k}}$ whose coefficient is positive is all 1 , logitp has the maximum value which is 0.0784 then $p=0.5196$, that is, $51.96 \%$.For example: a university student who fits every condition in the model--he is a junior or senior student in university; his father got a bachelor degree or above; he is the only child in his family; his monthly consumption is more than 600 yuan; his grades are outstanding; he has no part-time job experience; he has interpersonal relationship pressure. For him, the possibility that he choose to take part in the entrance exams for postgraduate schools will be more than $50 \%$. In 2015 , students who apply for postgraduate enrollment ratio (examination) occupy $22.9 \%{ }^{3}$ of all the students. This is a result that count in those students who failed in their last year postgraduate entrance exam and take the exam again that year, and if we remove them, the result is far less than $51.96 \%$.

The practical value of the model

Improving the applicants rate and success rate of undergraduates' applying for postgraduates is not only an effective way to relieve the employment pressure of college undergraduates ,but also an effective way to improve the level of running a university. What's more important, it is a reliable measure to cultivate talents for society construction. Nowadays, Universities in China spare no efforts to improve these two numbers.

For example: the student handbook states that "students who apply for post-graduate study and students who successfully become postgraduate students will be greatly rewarded ". Meanwhile, all kinds of promotional activities and are carried out and countless lectures are given to encourage students to apply for post-graduate study. There is an old saying to describe such no-overall-plan-for-a-fundamental -transformation situation:"treat the head when the head aches, treat the foot when the foot hurts", the effect of which, self-evidently, is not good. Under the background of the global financial crisis or economic weakness in China, the employment situation will face abnormal pressure; some majors will even have to deal with the risk of being cancelled. If universities don't make any measures to encourage students to apply for post graduate study until facing this situation, predictably, the goal of helping junior and senior students to avoid employment pressure won't be good. According to the conclusion of this model, the author put forward five suggestions to the practical value of the model:

First, universities should encourage freshman and sophomore students to make up their mind to apply for postgraduate study, especially male students. For those students who just get rid of high school pressure, after they enter University, their self-discipline will easily be reduced, and some of them will lose their interest in study, and even choose to drop out. Colleges and universities should make advantage of this model as soon as possible, identify those who want to be postgraduate students when they are freshman and carry out related activities and educate them with pertinence so as to help them form their goal and make their career plan. During the four years, universities should enhance academic atmosphere unceasingly, and ensure the external environment to be of good academic atmosphere. Most people will take it for granted that there are more female students applying for postgraduate study than male students. However, the model in this paper doesn't show this.

Secondly, encourage those students who are from relatively high income families and one-child families to apply for postgraduate study. As they have better economic support, compared with their peers whose families are under great economic pressure, these students from high income families or one-child families are more likely to chase further study.

Third, encourage those students whose fathers are well educated for graduate school. Generally speaking, those students' family income tends to be better and their parents have higher expectation for them. Colleges and universities should give these students more encouragement to apply for postgraduate study.

Fourthly, encourage those students who are under greater interpersonal pressure to apply for postgraduate study. These students tend to feel inferior, be introverted and self-enclosed. They can 
easily have emotional and psychological resistance to circumstance, which will lead to inferiority mentality. Universities should adjust their management method for those students. Based on the principle "avoiding emergency and accident", some universities tend to simply ignore those students as long as they don't cause any bad situation. In fact, universities should pay more attention to them, help them establish their study goal, encourage them to prove themselves with their outstanding grades and applying for postgraduate study successfully.

Fifth, whether students' majors are popular or not does not affect the students' willingness for further study. From this model, we find that no matter their majors are popular or not, students can apply for postgraduate study. The effect of major difference on their postgraduate study willingness is not as great as what we supposed. Universities should come up with specific encouragement policy for students of different major. For example, universities should encourage those whose majors are hard to find ideal jobs to apply for postgraduate study, so as to change their adverse employment situation ; for those whose majors are popular, universities should encourage them to continue their studies to improve their employment level.

\section{Acknowledgement}

An Analysis on the Factors Influencing College Students' Intention to Post-graduate Study Guangdong University of Finance \& Economics , 12GLL88001

\section{Reference}

[1] China Education Yearbook (1949-1981) [J] Beijing: Encyclopedia of China Publishing House .1984.

[2] Department of Education. National Development and Reform Commission issued in 2015 on the National Graduate enrollment plan notification. Department of Education [2015] 2. 2015-3-6.

[3] The number of college graduates nationwide during 2001 - 2015 .China Online Education .2014-12-05.

[4] Chen Zhifeng. Analysis of three factors that affect the number of graduate applicants [J]. Hangzhou University. Volume 27 No. 4. 1997,12.

[5] Xiao Zhanfeng. Students' willingness for graduate study report [J]. Statistics education. December 2008.

[6] Zheng Jun\&Yang Guang. In the perspective of rational choice theory - Sociological analysis of contemporary Chinese college students' motivation for postgraduate study [J]. Hubei Social Sciences. 2005,2.

[7] Shangguan Jian. Sociology Analysis for "postgraduate study craze" [J]. China Higher Education Research. 2007 ,No4.

[8] Lu Jie. Analysis on colleges students' motivation for postgraduate study [J]. Jiangsu University of Science and Technology (Social Science Edition). Volume 7, No. 4. 2007,12.

[9] Zhou Ye. Structure analysis on contemporary Postgraduate School Entrance Examination motivation factor [J]. ASSOCIATION FORUM. 2011 No.11.

[10] Liu Tianjun. Research on university students' motivation and influencing factors for Postgraduate Study [J]. Higher Education of Finance and Economics. 2013 March. 